\title{
Letters
}

\section{Lithotripsy in SCI patients}

The recently published paper by Di Lorenzo, Maleci and Williams ${ }^{1}$ throws light on a previously obscure aspect of one of our patients. This 31-year-old man had a spinal cord injury in 1988 from a C7-T1 dislocation. When first observed in 1991, there was a complete neurological lesion below the injury site with increased muscle tone, exaggerated tendon jerks, clonus and a hyperreflexic bladder with frequent incontinence. He was included as an example in a study of patients with atypical syndromes caudal to the injury site. ${ }^{2}$ Some months later he had recurrent symptoms of renal colic caused by a stone in the middle calices of his right kidney, diagnosed by sonography and urography. Lithotripsy was undertaken. The power output of the machine used was $15 \mathrm{kV}$ for a total of 850 shock waves. After the procedure he had urinary retention. Urodynamic examination revealed that the previous hyperreflexic bladder had changed to an areflexic one. The spastic leg symptoms were decreased, the sensory level was unchanged. He learned self-catheterisation and continued with this for about 4 months by which time the bladder had partially recovered its automatism with better compliance and without incontinence.

An MRI examination, suggested by the observation of Lorenzo et al, ${ }^{1}$ now discloses a cystic cavity extending for two vertebral segments just below the injury site. The

\section{Reply from Drs Di Lorenzo, Maleci, Williams}

We read with much interest the letter from Drs Tosi and Terrini, as the case that they report has many analogies with the one we presented in Paraplegia. ${ }^{1}$ As we stated in our article, the occurrence of a deterioration of neurological status after lithotripsy in SCI patients should be contemplated and the presence of a syrinx in the spinal cord should be ruled out before undertaking this procedure. Greater awareness of this possibility is desirable. The patient of Drs Tosi and Terrini shows that such occurrence is a significant danger. patient had changed in now having an atypical syndrome caudal to the injury site following the lithotripsy. He had post-traumatic syringomyelia. This observation confirms the opinion of the authors that lithotripsy may have important effects on SCI patients with post-traumatic syringomyelia. We feel that the incidence of post-traumatic syringomyelia, as revealed by the MRI follow-up, could be higher than $3 \%$. The change from 'a typical to an atypical syndrome' below the injury site may have some possible favourable effects on the daily living of these patients. ${ }^{2}$ Could a graded administration of shock waves reduce spasticity and/or bladder hyperreflexia in patients with a complete lesion and syringomyelic cavities below the injury site?

1 Di Lorenzo N, Maleci A, Williams BM. Severe exacerbation of post-traumatic syringomyelia after lithotripsy. Paraplegia 1994; 32: 694-696.

2 Tosi L, Righetti C, Terrini G, Zanette G. Atypical syndromes caudal to the injury site in patients following spinal cord injury. A clinical, neurophysiologic and MRI study. Paraplegia 1993; 31: 751-756.

\author{
L Tosi MD and G Terrini MD \\ Department of Rehabilitation \\ Don Calabria Hospital \\ 37024 Negrar, Verona, Italy
}

Drs Tosi and Terrini also prospect a therapeutic use of shock waves in selected cases of complete spinal lesion with sublesional syrinx; this is an interesting idea but it needs to be carefully considered and discussed on the basis of greater experience.

Nicola Di Lorenzo MD Alberto Maleci MD PhD Bernard Williams MD ChM FRCS

1 Di Lorenzo N, Maleci A, Williams BM. Severe exacerbation of post-traumatic syringomyelia after lithotripsy. Paraplegia 1994; 32: 694-696. 